\title{
Optimal Technology Subsidies vs Export Subsidies: A Strategic Approach
}

\author{
Hong Hwang ${ }^{\mathrm{a}}$ and Chao-cheng $\mathrm{Mai}^{\mathrm{b} *}$ \\ ${ }^{a}$ National Taiwan University and Academia Sinica \\ ${ }^{b}$ Tamkang University and Academia Sinica
}

\begin{abstract}
National governments, especially in developing countries, play a key role in certain international industries, particularly those high technology and high investment industries. By endogenizing the firm's technology choice, this paper has developed a strategic approach to examine the economic effects of technology subsidy and/or export subsidy on the technology and output decisions. The main findings of this paper are as follows: (1) If the domestic government can prescribe only one policy to improve its competitiveness in the international market, then export subsidy is superior to technology subsidy. (2) It does not matter whether the technology and export subsidies are implemented simultaneously or sequentially - both policies can lead to the first-best solution: cost minimization in the technology choice and Stackelberg leader position in the export market. (3) To reach the cost-minimizing technology level, the tax revenue required is higher under sequential than that under simultaneous policy implementation.
\end{abstract}

JEL Classification: F12, F13

Keywords: Technology subsidy, export subsidy, strategic trade policy

\section{Introduction}

Ever since the 1980s, there have been serious challenges on the traditional Heckscher-Ohlin trade theory, which is based on the assumption of perfect competition. Recognizing that international competition among firms in many industries is imperfectly competitive, the study of trade theory and policy under imperfect competition has become a new subject since the 1980s. Trade theorists began to focus on the profit-shifting motive for trade policy under oligopoly, notably including

" Corresponding author: Chao-cheng Mai, Research Center for Humanities and Social Sciences, Academia Sinica, 128 Sec. 2, Academia Rd., Nankang Taipei 11529, Taiwan. Tel: 886227821693 ext.130. Fax: 8862 27854160. E-mail: ccmai@gate.sinica.edu.tw. 
Brander and Spencer (1984, 1985), Spencer and Brander (1983), Venables (1985), Harris (1985), Eaton and Grossman (1986), Hwang and Mai (1991), Mai and Hwang (1987) and others. In particular, Brander and Spencer (1985) argued that if the domestic government can credibly pre-commit itself to pursuing a particular trade policy before firms make output decisions, then an export subsidy in a Cournot-Nash equilibrium is optimal and such an export subsidy can actually move the domestic firm to what would be, in the absence of a subsidy, the Stackelberg leader position. However, the World Trade Organization (WTO) explicitly forbids export subsidies, except for technology subsidies (or research and development (R\&D) subsidies). Perhaps for this reason, technology subsidies seem to be more important practically than export subsidies. In this aspect, Spencer and Brander (1983), hereafter referred to as "SB", developed the first strategic technology subsidy model which consists of three stages. In stage 1, both the domestic and foreign governments set subsidies to help their own firms to compete in a third country market; in stage 2 , firms simultaneously select technology levels; and in stage 3 firms play a Cournot output game. They show, among other things, that a rise in the domestic technology subsidy raises the domestic technology level but reduces the foreign technology level in the case where the foreign firm's technology reaction curve is downward-sloping. Articles in this direction includes Choi (1995), Miyagiwa and Ohno (1995, 1999), Bagwell and Staiger (1994), Muniagurria and Singh (1997), Butler and Mitchell (1998), García-Quevedo (2004), Lach (2002), Lahiri and Ono (1999), Petrakis and Poyago-Theotoky (2002) and Zhou et al (2002).

As a matter of fact, different strategic policies (such as technology and export subsidies) may exert different effects on the technology choice. It then becomes clear that if policy makers do not have relevant information about the firm's technology choice, the government could very likely adopt a wrong type of policy. Rather than taking the technology as given, the cost level is endogenized by assuming that it is a result of costly investment, like $\mathrm{R} \& \mathrm{D}$, by forward-looking and optimizing agents. More specifically, this paper investigates the effect of profit-shifting strategic trade policy on the technology choice, namely, how the pursuit of profit-shifting technology and/or export policies can affect the long-run technology choice by exporters ${ }^{1}$. To this end, this paper will pursue the following issues:

(i) the effects of technology and export subsidies on the technology choice and the comparison of the superiority of both policies;

(ii) the welfare implications of the two policies if they are implemented simultaneously or sequentially; and

(iii) which policy implementation requires a higher government subsidy expenditure.

This paper, though developed along the line of $\mathrm{SB}$, is quite different from that paper in several aspects. First, the setting between the two papers is different. This paper focuses on technology choice while SB focuses on R\&D. This paper examines both simultaneous and sequential games with respect to the choices of the export and

\footnotetext{
${ }^{1}$ In the spirit of DeGraba's work (1990), Choi (1995) compared the effects of optimal tariffs on the technology choice of exporters under the discriminatory tariffs regime and the MFN clause. It is shown that a lower marginal cost technology will be chosen in equilibrium under the MFN clause.
} 
technology subsidies and compare their efficacy, while only the simultaneous game is considered in SB. Second, SB examines the cases where both governments (i.e. both home and foreign) simultaneously implement R\&D subsidies. This paper on the other hand examines the cases with unilateral intervention. It is worth mentioning that unilateral intervention normally bears important implications in comparison with bilateral intervention in strategic trade theory and has been the center of the discussions in the literature. For example, the main focus of the seminal paper by Brander and Spencer (1985) is on unilateral intervention. Hence, this paper's model may look more restrictive than SB in one way while it is complementary to SB in another. Third, this paper compares the subsidy payments under the simultaneous and the sequential games, but this is not pursued in SB. This extension has important policy implications. Note that many empirical studies in public economics have found that the social cost of an extra dollar in public funds, due to the taxation distortion, is greater than unity. If this concept is applied to the model in this paper, it will be found that the social welfare is higher under the sequential game than that under the simultaneous game.

The structure of the paper is as follows. Section 2 describes technology distortion under free-trade equilibrium. Section 3 considers optimal technology subsidy only. In Section 4, optimal export subsidy is examined. Section 5 assumes that the domestic government adopts technology and export subsidies simultaneously and then investigates their welfare implications. Section 6 considers instead that technology and export subsidies are implemented sequentially and discuss its welfare consequences. In Section 7, the ranking of the two policy combinations is made. Concluding remarks are provided in the final section.

\section{Technology Distortion under Free-trade Equilibrium}

The simplest possible structure capable of bringing out the main points is used. There are two competing firms: one domestic firm and one foreign firm. The model is similar to Brander and Spencer (1985). Both firms produce only for a third-country market and there is no consumption in the producing countries. The free-trade equilibrium is characterized by a two-stage game. In the first stage, the domestic firm chooses its best technology level by selecting a level of marginal cost, assuming the foreign firm' s technology level is pre-determined. In this paper, the domestic firm's technology level is characterized by $F(c)$, where $c$ is marginal cost and $F(c)$ can be taken as R\&D outlay or the price of the acquired technology with property of $F^{\prime}<0$ and $F^{\prime \prime}>0$. That is, a lower marginal cost is achieved at the expense of a higher fixed cost. In fact, $F$ can be thought of as an irreversible investment in cost-reducing R\&D. In general, technology may be characterized as "backward" (with a high marginal cost and a low fixed cost) or "advanced" (with a low marginal cost and a high fixed cost). In the second stage, the domestic firm competes with the foreign firm in the third-country market. Within this framework, a sub-game perfect equilibrium can be obtained as the solution. Under this setting, the profit functions of the two firms are specified as follows:

$$
\pi\left(q, q^{*}\right)=R\left(q, q^{*}\right)-c q-F(c)
$$




$$
\pi^{*}\left(q, q^{*}\right)=R^{*}\left(q, q^{*}\right)-c^{*} q^{*}-F^{*}\left(c^{*}\right)
$$

where $R$ is the total revenue and $q$ is the output of the domestic firm; variables with asterisks denote that they are associated with the foreign firm.

The equilibrium is solved in the standard backward fashion. In stage two, each firm maximizes its profits with respect to its own output. The Cournot-Nash equilibrium is characterized by the following first-order conditions:

$$
\begin{aligned}
& \pi_{q}=R_{q}-c=0 \\
& \pi_{q^{*}}^{*}=R_{q^{*}}^{*}-c^{*}=0
\end{aligned}
$$

The following conditions are also assumed to have been satisfied:

$$
\begin{aligned}
& \pi_{q q^{*}}=p^{\prime \prime} q+p^{\prime}<0 ; \pi_{q^{*} q}^{*}=p^{\prime \prime} q^{*}+p^{\prime}<0 \\
& \pi_{q q} \equiv p^{\prime \prime} q+2 p^{\prime}<\pi_{q q^{*}} ; \pi_{q^{*} q^{*}}^{*} \equiv p^{\prime \prime} q^{*}+2 p^{\prime}<\pi_{q^{*} q}^{*}
\end{aligned}
$$

where $p$ is the price of the output and "primes" denote derivatives.

Equation (5) means that the marginal revenue declines with an increase in the output of the other firm. This is equivalent, given the satisfaction of the second-order conditions, to reaction functions being downward-sloping. On the other hand, equation (6) is the second-order condition for profit maximization. Equation (6) implies that the own effect of output on marginal profit dominates the cross effect, which is a popular assumption in strategic trade policy literature, see for example, Brander and Spencer (1985). Moreover, conditions (5) and (6) imply that:

$$
D \equiv \pi_{q q} \pi_{q^{*} q^{*}}^{*}-\pi_{q q^{*}} \pi_{q^{*} q}^{*}>0
$$

which is the stability condition for profit maximization. Assuming the second-order and stability conditions are all satisfied, the optimal output levels of the domestic and the foreign firms can be derived from (3) and (4) which are functions of the marginal costs of the two firms, i.e., $q\left(c, c^{*}\right)$ and $q^{*}\left(c, c^{*}\right)$. Using this property, the second-stage problem can be pursued as follows. For a given foreign marginal cost $c^{*}$, the domestic firm chooses $c$ in stage one, so as to maximize its profits:

$$
\pi\left(c, c^{*}\right)=R\left(q\left(c, c^{*}\right), q^{*}\left(c, c^{*}\right)\right)-c q\left(c, c^{*}\right)-F(c)
$$

The technology equilibrium of the domestic firm is derivable as follows:

$$
\frac{d \pi}{d c}=\frac{\partial \pi}{\partial q} q_{c}+\frac{\partial \pi}{\partial q^{*}} q_{c}^{*}+\frac{\partial \pi}{\partial c}=0 \text { or } R_{q^{*}} q_{c}^{*}=q+F_{c}<0
$$

where $\frac{\partial \pi}{\partial q}=0$ from (3), $R_{q^{*}}=p^{\prime} q<0$ and $q_{c}^{*} \equiv \frac{d q^{*}}{d c}=\frac{-\pi_{q^{*} q}^{*}}{D}>0$. 
Before interpreting (9), the property of the domestic firm's total cost function, which is defined as $T C=c q+F(c)$, should be discussed. It is normally expected that the total cost function is convex with respect to technology, i.e., $\frac{\partial^{2} T C}{\partial c^{2}}>0$ as depicted in Figure 1. Note that the right-hand side of (9) is equivalent to $\frac{\partial T C}{\partial c}=q+F_{c}$. As shown in Figure 1, the total cost is minimized at $\bar{c}$ when $\frac{\partial T C}{\partial c}=q+F_{c}=0$. With this in mind, it follows from (9) that $\left(q+F_{c}\right)=R_{q^{*}} q^{*}{ }_{c}<0$ which implies that the optimal technology

is at the left-hand side of the cost-minimizing, say $c_{1}$ as depicted in Figure 1. Therefore, anticipating the output rivalry in the last-stage game, the domestic firm chooses a technology level which is more advanced (i.e. a lower $c$ ) than the cost-minimizing technology level. In other words, the duopolistic interaction between firms causes the domestic firm to twist its technology choice away from the regular cost-minimizing technology level in order to accrue more profits from the output game. If there were no foreign firm, the domestic firm would have chosen the cost-minimizing technology, given any output level. In the presence of the foreign firm, the domestic firm's profits are maximized if the marginal gain from a more advanced technology (i.e. $R_{q^{*}} q_{c}{ }_{c}$ ) is equal to its marginal cost (i.e. $q+F_{c}$ ). However, as the domestic firm is not minimizing its total cost with respect to technology, there is a technology distortion from the domestic social welfare point of view. Moreover, this more advanced technology still falls short of the level which moves the domestic firm to the Stackelberg leader position in the output space, there is room for the domestic government to intervene so as to raise its national welfare.

Figure 1: The total cost function with respect to technology level

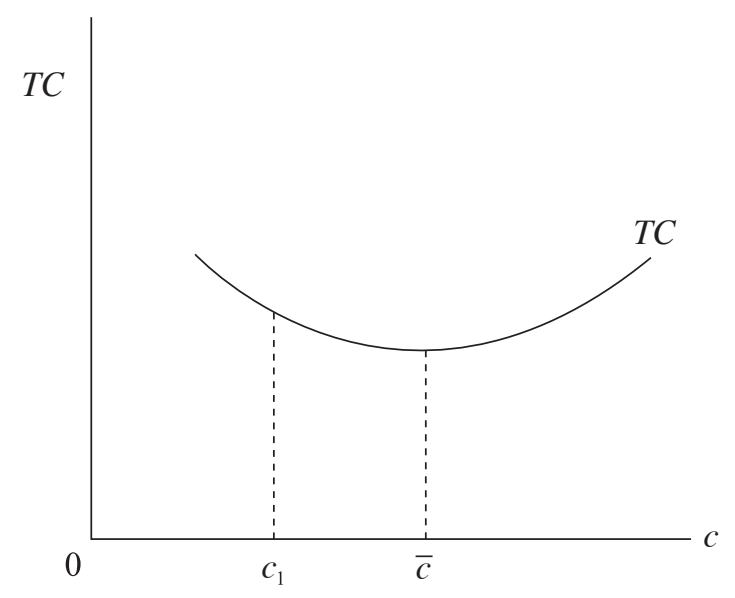

It is assumed that the government can use either technology and/or export subsidy to help its firm to compete with the foreign firm in the third-country market. In so doing, the equilibrium is characterized by a three-stage game. In the first stage, the government 
chooses the optimal export and/or technology subsidy policy which is followed by the domestic firm's technology choice in the second stage and then by the Cournot competition in output space in the third stage. The subgame perfect equilibrium shall be examined, given the assumption that the government understands the structure of the industry and is able to set a credible subsidy in advance of the output and technology decisions by firms.

Under this situation, the profit functions of the two firms are specified as follows:

$$
\begin{aligned}
& \pi\left(q, q^{*}\right)=R\left(q, q^{*}\right)-c q-F(c)+s q+z F(c) \\
& \pi^{*}\left(q, q^{*}\right)=R^{*}\left(q, q^{*}\right)-c^{*} q^{*}-F^{*}\left(c^{*}\right)
\end{aligned}
$$

where $s$ and $z$ denote the export and technology subsidies, respectively.

The first-order conditions for profit maximization in this (third) stage are:

$$
\begin{aligned}
& \pi_{q}=R_{q}-c+s=0 \\
& \pi_{q^{*}}^{*}=R_{q^{*}}^{*}-c^{*}=0
\end{aligned}
$$

Assuming both the second-order and stability conditions are met, the comparative static effects of $s, z$ and $c$ on $q$ and $q^{*}$ are derivable as follows:

$$
\begin{aligned}
& q_{c} \equiv \frac{d q}{d c}=\frac{\pi^{*}{ }_{q^{*} q^{*}}}{D}<0 \\
& q_{c}^{*} \equiv \frac{d q^{*}}{d c}=\frac{-\pi^{*} q^{*} q^{*}}{D}>0 \\
& q_{s} \equiv \frac{d q}{d s}=\frac{-\pi^{*}{ }_{q^{*} q^{*}}}{D}>0 \\
& q^{*} \equiv \frac{d q^{*}}{d c}=\frac{\pi^{*}{ }^{*} q^{*}}{D}<0 \\
& q_{z} \equiv \frac{d q}{d z}=0 \\
& q^{*} \equiv \frac{d q^{*}}{d z}=0
\end{aligned}
$$

which imply that $q=q(s, c)$ and $q^{*}=q^{*}(s, c)$.

This completes the third-stage analysis. Now the second-stage problem will be examined. In the second stage, the domestic firm chooses c so as to maximize its profits as specified in (10) which yields the following first-order condition:

$$
\frac{d \pi}{d c}=\frac{\partial \pi}{\partial q} q_{c}+\frac{\partial \pi}{\partial q^{*}} q^{*}{ }_{c}+\frac{\partial \pi}{\partial c}=0 \text { or } R_{q^{*}} q^{*}{ }_{c}+z F_{c}=q+F_{c}
$$


where $\frac{\partial \pi}{\partial q}=0$ from (12).

Note that the domestic firm's technology cost is minimized when $q+F_{c}=0$ for any given $q$. It then follows from (15) that a positive technology subsidy would deviate the domestic firm's technology equilibrium farther away from the cost-minimizing level.

Assuming the second-order condition is satisfied, the effects of $z$ and $s$ on $c$ is derivable by totally differentiating (15) with respect to $c, z$ and $s$ :

$$
\begin{gathered}
C_{\mathrm{z}} \equiv \frac{d c}{d z}=-\frac{\pi_{c z}}{\pi_{c c}} \\
C_{s} \equiv \frac{d c}{d s}=-\frac{\pi_{c s}}{\pi_{c c}}
\end{gathered}
$$

where $\pi_{c z}=F_{c}<0$,

$$
\pi_{c s}=\left(R_{q^{*} q} q_{s}+R_{q^{*} q^{*}} q_{s}^{*}\right) q_{c}^{*}+R_{q^{*}} q_{c s}^{*}-q_{s}
$$

In general, the sign of $\pi_{c s}$ is ambiguous, as the sign of $q_{c s}^{*}$ depends on $p^{\prime \prime \prime}$, whose sign is indeterminate. Nevertheless, if it is assumed that the demand function is linear, then $\pi_{c s}=-q_{s}<0^{2}$ which together with $\pi_{c z}<0$ implies that $c_{z}<0$ and $c_{s}<0$. It is assumed that these are the cases in the following analysis.

The optimal domestic technology and /or export subsidies will be investigated in the following sections.

\section{Optimal Technology Subsidies}

Assume first that the government imposes only the technology subsidy. The optimal technology subsidy is found by maximizing the domestic welfare $W$, which is the profit of the domestic firm less the cost of the subsidy, with respect to $z$ :

$$
\operatorname{Max}_{z} W(z)=\pi-z F(c)
$$

The first-order condition for the welfare maximization is given by :

$$
\frac{d W}{d z}=\frac{\partial \pi}{\partial c} c_{z}+\frac{\partial \pi}{\partial z}-F-z F_{c} c_{z}=0
$$

Since $\frac{\partial \pi}{\partial c}=0$ from (15) and $\frac{\partial \pi}{\partial z}=F,(18)$ reduces to:

$$
-z F_{c} c_{z}=0 \text { or } z=0
$$

\footnotetext{
${ }^{2}$ Under a linear demand, we have: $\pi_{c s}=\left(p^{\prime} q_{s}+2 p^{\prime} q_{s}^{*}\right) q_{c}-q_{s}=p^{\prime}\left(\frac{-2 p^{\prime}}{D}+\frac{2 p^{\prime}}{D}\right) q_{c}-q_{s}=-q_{s}<0$
} 
The optimal technology subsidy is nil. This is because the domestic firm has already taken into account the rivalry effect in the export market while determining its optimal technology. There is no room for the government to intervene. Therefore:

Proposition 1. The technology subsidy cannot remove or reduce the technology distortion. The optimal technology policy is laissez-faire.

\section{Optimal Export Subsidies}

Alternatively, it can be assumed that the government imposes only the export subsidy, prior to the domestic firm's technology choice. In this case, the objective of the domestic government is to maximize its welfare with respect to $s$. That is:

$$
\underset{s}{\operatorname{Max}} W(s)=\pi-s q
$$

The first-order condition for welfare-maximization is derivable as:

$$
\begin{aligned}
& \frac{d w}{d s}=\frac{\partial \pi}{\partial c} \frac{\partial c}{\partial s}+\frac{\partial \pi}{\partial s}+\frac{\partial \pi}{\partial q} \frac{\partial q}{\partial s}+\frac{\partial \pi}{\partial q^{*}} \frac{\partial q^{*}}{\partial s}-q-s \frac{d q}{d s}=0 \text { or } \\
& s=\frac{p^{\prime} q q_{s}^{*}}{q_{c} c_{s} q_{s}}>0
\end{aligned}
$$

as $\frac{\partial \pi}{\partial c}=0$ from (15), $\frac{\partial \pi}{\partial q}=0$ from (12), $c_{s}<0, c_{z}<0$ by (16) and $q_{s}>0$ and $q_{s}^{*}<0$ by (14).

Equation (21) indicates that the optimal export subsidy is positive, implying that an export subsidy can raise the national welfare. In general, as $c_{s}<0\left(c_{s}<0\right.$ if the demand is linear), the optimal export subsidy tends to aggravate the technology distortion, i.e. the technology choice of the domestic firm is farther away from the cost-minimizing technology level. But more advanced technology can increase the market share as well as the profits earned from the international market, which definitely makes the country better off. It should be noted that the optimal export subsidy does not move the domestic firm to the Stackelberg leader position in the output space ${ }^{3}$. Therefore:

Proposition 2. The domestic country has a unilateral incentive to offer an export subsidy to its firm. The optimal export subsidy aggravates the technology distortion and does not move the domestic firm to the Stackelberg leader position in the output space.

Proposition 2 is in sharp contrast with Brander and Spencer's (1985) result that an export subsidy if chosen optimally will move the home firm to what would be the Stackelberg leader position in the output space. The ranking between the technology

\footnotetext{
${ }^{3}$ The export subsidy rate has to be at $S=\frac{R_{q^{*}} q_{s}^{*}}{q_{s}}$ to move the domestic firm to the Stackelberg leader position. See also the proof in footnote 5 .
} 
and export subsidies is straightforward. Note that the welfare levels are the same if the subsidy rates are zero (i.e. $W(z=0)=W(s=0)$ ). Because the optimal technology subsidy is zero while the optimal export subsidy is positive, it can be concluded that the export subsidy policy is superior to the technology subsidy policy. Thus:

Proposition 3. The welfare is necessarily higher under optimal export subsidies than that under optimal technology subsidies.

From the above analysis, it is clear that neither technology subsidy nor export subsidy alone can remove the technology distortion. In what follows, it will be assumed that the domestic country can impose both technology and export subsidies either simultaneously or sequentially and then examine their welfare implications in the following two sections respectively.

\section{Simultaneous Policy Implementation}

The game now consists of three stages. The second-stage technology choice and the third-stage output decision problem can be found in Section 2. The first-stage problem is characterized as follows:

$$
\underset{s, z}{\operatorname{Max}} W(s, z)=\pi-s q-z F(c)
$$

where $q=q(c, s, c(s, z))$ and $q^{*}=q^{*}(c, s, c(s, z))$.

The first-order conditions require:

$$
\begin{aligned}
& \frac{\partial W}{\partial s}=\frac{\partial \pi}{\partial c} c_{s}+\frac{\partial \pi}{\partial s}+\frac{\partial \pi}{\partial q} q_{s}+\frac{\partial \pi}{\partial q^{*}} q_{s}^{*}-q-s \frac{d q}{d s}-z F_{c} c_{s}=0 \\
& \text { or } R_{q^{*}} q_{s}^{*}-s\left(q_{c} c_{s}+q_{s}\right)-z F_{c} c_{s}=0 \\
& \frac{\partial W}{\partial z}=\frac{\partial \pi}{\partial c} c_{z}+\frac{\partial \pi}{\partial z}-s \frac{d q}{d z}-z F_{c} c_{z}=0 \\
& \text { or } z=\frac{s q_{c}}{F_{c}}
\end{aligned}
$$

with $\frac{\partial \pi}{\partial c}=0$ from (15) and $\frac{\partial \pi}{\partial q}=0$ from (12).

Solving (23) and (24) simultaneously for $s$ and $z$ yields:

$$
s=\frac{R_{q^{*}} q_{s}^{*}}{q_{s}}>0
$$




$$
z=\frac{R_{q^{*}} q_{s}^{*}}{F_{c}}<0
$$

where $R_{q^{*}}=p^{\prime} q<0, q_{s}^{*}<0, q_{s}>0$ (by (14)) and $F_{c}<0$ by assumption.

Note that the optimal $s$ and $z$ derived in this case can not only remove the technology distortion, but also lead the domestic firm to the Stackelberg leader position. The former can be proved by substituting (25-2) into $(15)^{4}$, while the latter by substituting (25-1) into $(12)^{5}$. This leads to:

Proposition 4. If both the technology and the export subsidies are adopted simultaneously, the domestic country can reach its first-best solution - cost minimization in its technology choice and the Stackelberg leader position in the export market.

This result is similar to the one derived in SB. They found that the government should impose a R\&D tax to restore the cost minimization condition in the R\&D space and use an export subsidy to move the domestic firm to the Stackelberg leader position in the export market.

\section{Sequential Policy Implementation}

In Section 5, it was assumed that the government sets both the export subsidy and the technology subsidy at the same time. In this section, another scenario will be examined: where the technology subsidy and the export subsidy are implemented sequentially. More specifically, the game consists of four stages. In the first stage, a technology subsidy is determined, which is then followed by the technology choice in the second stage. An export subsidy is chosen in the third stage and the output decision in the fourth stage.

The last stage output decision is the same as the one derived before. The third-stage optimal export subsidy is solved in Brander-Spencer's (1985) manner:

$$
\underset{s}{\operatorname{Max}} W(s)=\pi-s q-z F(c)
$$

The first-order condition requires:

$$
W_{s} \equiv \frac{d W}{d s}=\frac{\partial \pi}{\partial q} q_{s}+\frac{\partial \pi}{\partial q^{*}} q_{s}^{*}+\frac{\partial \pi}{\partial s}-s q_{s}-q=0
$$

\footnotetext{
${ }^{4}$ By substituting (25-2) into (15), we obtain: $R_{q^{*}} q_{c}^{*}+z F_{c}=q+F_{c} \quad R_{q^{*}} q_{c}^{*}+\frac{R_{q^{*}} q_{s}^{*}}{F_{c}} F_{c}=q+F_{c}$ $R_{q^{*}}\left(q_{c}^{*}+q_{s}^{*}\right)=q+F_{c} \quad \because q_{c}^{*}=-q_{s}^{*}$ by (11) $\therefore q+F_{C}=0$

${ }^{5}$ Substituting (25-1) into (12) yields: $R_{q}-c+s=R_{q}-c+\frac{R_{q^{*}} q_{s}^{*}}{q_{s}}=R_{q}+R_{q^{*}} \frac{d q^{*}}{d q}-c=0$ which is exactly the first-order condition, if the domestic firm is a Stackelberg leader in an output game with no subsidy.
} 
or $\quad s=\frac{R_{q^{*}} q_{s}^{*}}{q_{s}}>0$

where $\frac{\partial \pi}{\partial q}=0$ by (12).

It is obvious that the optimal export subsidy is to lead the domestic firm to the Stackleberg leader position in the output space. Note that $q=q\left(c, c^{*}, s\right)$ from the fourth stage problem. Then the comparative static effect of $c$ on $s$ can be evaluated as follows:

$s_{c}=\frac{d s}{d c}=\frac{-W_{s c}}{W_{s s}}<0$

where $W_{s s}<0$ by the second-order condition and $W_{s c}=\left(p^{\prime \prime} Q_{c} q+p^{\prime} q_{c}\right) q_{s}{ }_{s}<0$ as long as the demand is not too concave. It is assumed this is the case. Equation (28) implies that a higher domestic marginal cost leads to a lower export subsidy. If the marginal cost of the domestic firm is higher, the closer the distance between the current reaction function and the reaction function passing through the Stackelberg leader position, thus the lower the optimal export subsidy. It warrants mention that $q$ is not a function of $z$; hence the technology subsidy gives no direct effect on the optimal choice of $s$. Using the property of $s=s(c)$ with $s_{c}<0$, the maximization problem for the second stage can be formed:

$$
\operatorname{Max}_{c} \pi(c)=R\left(q, q^{*}\right)-c q-F(c)+s(c) q+z F(c)
$$

The first-order condition requires:

$$
\begin{aligned}
& \frac{d \pi}{d c}=\frac{\partial \pi}{\partial q} \frac{\partial q}{\partial c}+\frac{\partial \pi}{\partial q^{*}} \frac{\partial q^{*}}{\partial c}+\frac{\partial \pi}{\partial c}=0 \\
& \text { or } R_{q^{*}} \frac{d q^{*}}{d c}+s_{c} q+z F_{c}=q+F_{c}
\end{aligned}
$$

where $\frac{\partial \pi}{\partial q}=0$ from (12) and $\frac{d q^{*}}{d c}=q_{c}^{*}+q_{s}^{*} s_{c}$.

Since $s_{c}<0$, the export subsidy policy moves the technology equilibrium farther away from the cost-minimizing level. The intuition for this outcome is clear. The higher the output, the more subsidies the firm can receive from the government. Anticipating this opportunity, the domestic firm has an incentive to adopt a more advanced technology. The comparative static effect of $z$ on $c$ is no longer ambiguous as $s$ is not a function of $z$ in the current case. Apparently:

$$
\frac{d c}{d z}=-\frac{\pi_{c z}}{\pi_{c c}}=-\frac{F_{c}}{\pi_{c c}}<0
$$


Equation (31) shows that an increase in technology subsidy necessarily reduces the marginal cost of the domestic firm. The higher the value of $z$, the lower is the effective price of technology (which is measured by $(l-z) F(c)$ ) paid by the domestic firm. Hence, the domestic firm has an incentive to choose a more advanced and expensive technology.

Finally, the first-stage technology subsidy problem can be solved as follows:

$$
\underset{z}{\operatorname{Max}} W(c)=\pi-s q-z F(c)
$$

The first-order condition requires:

$$
\begin{aligned}
& \frac{d W}{d z}=\frac{\partial \pi}{\partial c} c_{z}+\frac{\partial \pi}{\partial z}-s_{c} c_{z} q-s \frac{d q}{d z}-F-z F_{c} c_{z} \\
& \text { or } \quad z=\frac{-s_{c} q-R_{q^{*}} q_{c}^{*}}{F_{c}}<0
\end{aligned}
$$

where $\frac{\partial \pi}{\partial c}=0$ from (30), $\frac{\partial \pi}{\partial z}=F, s \frac{d q}{d z}=R_{q^{*}} \frac{d q^{*}}{d z},{ }^{6}$ and $q_{c}^{*}>0$ by (14).

Consequently, the optimal technology subsidy is negative (i.e. $z<0$ ) as $F_{c}<0, s_{c}<0, R_{q^{*}}<0$, and $\frac{d q^{*}}{d c}>0$. Substituting (33) into (30), the following is
obtained:

$$
q+F_{c}=0
$$

As a result:

Proposition 5. Assume a technology subsidy is implemented before the technology choice, followed by an export subsidy being implemented before the output choice. The optimal technology subsidy is to remove the entire technology distortion, leading the domestic firm to choose the cost-minimizing technology. On the other hand, the optimal export subsidy is to move the domestic firm to the Stackelberg leader position. Hence, the first-best solution is ensured.

The discussion above has shown that technology and export subsidies in either the 3 -stage or the 4-stage game can lead to the first-best solution. An interesting question naturally arises: which policy menu requires a higher subsidy expenditure (or cost)? This question will be addressed in the next section.

$$
\begin{aligned}
& { }^{6} s \frac{d q}{d z}=R_{q^{*}} \frac{q_{s}^{*}}{q_{s}} \frac{d q}{d z}=R_{q^{*}} \frac{q_{s}^{*}}{q_{s}}\left(q_{c}+q_{s} s_{c}\right)=R_{q^{*}}\left(-q_{s}^{*}+q_{s}^{*} s_{c}\right) \quad\left(\because q_{s}=-q_{c}\right)=R_{q^{*}}\left(q_{c}^{*}+q_{s}^{*} s_{c}\right) \quad\left(\because q_{s}^{*}=-q_{c}^{*}\right) \\
= & R_{q^{*}} \frac{d q^{*}}{d c} \quad\left(\because q^{*}=q^{*}(s(c), c)\right)
\end{aligned}
$$




\section{The Ranking of the Two Policy Menu}

Use a subscript 3 to denote variables associated with the 3-stage game and a subscript 4 the 4 -stage game. Define the total government subsidy budget in the 3 -stage game as $T_{3}$ and that in the 4-stage game as $T_{4}$. Note that given any $q$ and $c$, the welfare under the 3-stage game is the same as the one under the 4-stage game. Denote the subsidy difference as $\Delta$, which is defined as:

$$
\begin{aligned}
& \Delta=T_{4}-T_{3} \\
& =[s q+z F(c)]_{4}-[s q+F(c)]_{3} \\
& =[z F(c)]_{4}-[z F(c)]_{3} \\
& =\left(z_{4}-z_{3}\right) F(c)
\end{aligned}
$$

Two notes are warranted here. First, $z<0$ is in both cases. Second, the first-order condition for profit-maximization in the output stage is $\pi_{q}=R_{q}-c+s=0$ either in the 3 -or in the 4-stage game. Given the same $q$ and $c$, the export subsidy required to produce the given $q$ is the same in both cases, i.e. $s_{3}=s_{4}$. But the optimal technology subsidy (tax) rates are different. Moreover, from (30), the following is obtained:

$$
z_{4}=\frac{q+F_{c}-R_{q^{*}}\left(q_{c}^{*}+q_{s}^{*} s_{c}\right)-s_{c} q}{F_{c}}
$$

Alternatively, from (15):

$$
z_{3}=\frac{q+F_{c}-R_{q^{*}} q_{c}^{*}}{F_{c}}
$$

Substituting (36) and (37) into (35):

$$
\Delta=\frac{F}{F_{c}}\left[q+F_{c}-R_{q^{*}}\left(q_{c}^{*}+q_{s}^{*} s_{c}\right)-s_{c} q-q-F_{c}+R_{q^{*}} q_{c}^{*}\right]
$$

For any given $q$ and $c$, the subsidy difference reduces to:

$$
\Delta=\frac{-F s_{c}}{F_{c}}\left(R_{q^{*}} q_{s}^{*}+q\right)<0 \text {, as } s_{c}<0, F_{c}<0 \text {, and } q_{s}^{*}<0
$$

Since the technology subsidy is negative in both cases, equation (35-2) shows that tax revenue under the 4-stage game exceeds the one under the 3-stage game. Therefore:

Proposition 6. It does not matter whether the technology and export subsidy policies are implemented simultaneously or sequentially, they can always achieve the firstbest solution. But the tax revenue is higher under the 4-stage game than that under the 3-stage game. 
The intuition behind this result is quite straightforward. According to the concept of subgame perfect equilibrium, the domestic firm can foresee the relation between $s$ and $c$ in the 4-stage game. As $s_{c}<0$, the domestic firm has an incentive to choose a more advanced technology (i.e. a lower $c$ ) so as to receive more export subsidy from the government. This would deviate the firm's optimal technology level farther away from the socially desirable level (i.e. the cost-minimizing technology). Consequently, it requires a higher technology tax to correct this distortion. Given the same equilibrium level of technology under the 3-stage and the 4-stage games, the tax revenue is therefore higher under the 4-stage game than that under the 3-stage game. Indeed, Proposition 6 bears some policy implications. Note that once an export subsidy policy is adopted, the domestic government's revenue to pay the export subsidy will typically be raised by some form of distortionary taxation. Most previous studies in trade literature have assumed that the social cost of public funds, including the revenues from taxation, is unity: an extra dollar earned in profits by the home firm has the same social valuation as an extra dollar in subsidy payments forgone by the home government. Not surprisingly, this assumption is rather restrictive from the viewpoint of public finance. For example, Snow and Warren (1996) have found that the social cost of an extra dollar in subsidy payments lies between 1.195 and 1.236. Based on his calculations for the US economy, Browning (1987) asserts that the social cost of subsidy lies between 1.32 and 1.47. Stuart (1984) calculates the marginal excess burden from taxes on labor income in the United States and has found the figure is roughly 1.5 times Browning's estimate. If their findings are taken into account and it is assumed that the social cost (benefit) of an extra dollar in subsidy payment (tax revenue) is higher than one (Neary (1994)), then the social welfare is necessarily higher under the 4-stage game than that under the 3 -stage game.

\section{Concluding Remarks}

National governments, especially in developing countries, play a key role in certain international industries, particularly those involving high technology and high investment. By endogenizing the firm's technology choice, this paper has developed a strategic approach to examine the economic effects of technology subsidy and/or export subsidy on the technology and output decisions. The main findings of this paper are briefly summarized as follows.

(1) If the domestic government can prescribe only one policy to improve its competitiveness in the international market, then export subsidy is superior to technology subsidy.

(2) It does not matter whether the technology and export subsidies are implemented simultaneously or sequentially, both policies can lead to the first-best solution: cost minimization in the technology choice and the Stackelberg leader position in the export market.

(3) To reach the cost-minimizing technology level, the tax revenue required is higher under sequential policy implementation than that under simultaneous policy implementation. 
This analysis generates at least one important policy implication: it has shown that, with export subsidies available, countries would not choose to subsidize their technology. Nevertheless, because GATT codes effectively restrict direct export subsidies, the setting in which only technology subsidies are available may be viewed as the most relevant case.

\section{References}

Bagwell, K. and R.W. Staiger, 1994, "The Sensitivity of Strategic \& Corrective R\&D Policy in Oligopolistic Industries," Journal of International Economics 36, 133 150.

Brander, J.A. and B.J. Spencer, 1984, "Tariff Protection and Imperfect Competition," in: Henryk Kierzkowski, ed., Monopolistic Competition and International Trade (Oxford University Press), 194-206.

Brander, J.A. and B.J. Spencer, 1985, "Export Subsidies and International Market Share Rivalry," Journal of International Economics 18, 83-100.

Browning, E.K., 1987, "On the Marginal Welfare Cost of Taxation," American Economic Review 77, 11-23.

Butler, A. and S.K. Mitchell, 1998, "Government Subsidies of R\&D in a Product Cycle Framework: US-Japan Simulations," Review of International Economics 6, 386400.

Choi, J.P., 1995, "Optimal Tariffs and the Choice of Technology: Discriminatory Tariffs vs. the Most Favored Nation," Journal of International Economics 38, 143-160.

DeGraba, P., 1990, "Input Market Price Discrimination and the Choice of Technology," American Economic Review 80, 1246-1253.

Eaton, J. and G.M. Grossman, 1986, “Optimal Trade and Industrial Policy under Oligopoly,” Quarterly Journal of Economics 101, 383-406.

García-Quevedo, J., 2004, "Do Public Subsidies Complement Business R\&D? A MetaAnalysis of the Econometric Evidence," Kyklos 57, 87-102.

Harris, R., 1985, "Why Voluntary Export Restraints are 'Voluntary'," Canadian Journal of Economics 18, 799-809.

Hwang, H. and C.C. Mai, 1991, "Optimum Discriminatory Tariffs under Oligopolistic Competition,” Canadian Journal of Economics 24, 693 - 702.

Lach, S., 2002, "Do R\&D Subsidies Stimulate or Displace Private R\&D? Evidence from Israel," Journal of Industrial Economics 50, 369-390.

Lahiri, S. and Y. Ono, 1999, "R\&D Subsidies Under Asymmetric Duopoly: A Note," The Japanese Economic Review 50, 104-111.

Mai, C.C., and H. Hwang, 1987, "Domestic Export Subsidy and Foreign Welfare," Economics Letters 23, 185-188.

Miyagiwa, K. and Y. Ohno, 1995, "Closing the Technology Gap under Protection," American Economic Review 85, 755-770.

Miyagiwa, K. and Y. Ohno, 1999, "Credibility of Protection and Incentives to Innovate," International Economic Review 40, 143-163. 
Muniagurria, M. E. and N. Singh, 1997, "Foreign Technology, Spillovers, and R\&D Policy," International Economic Review 38, 405-430.

Neary, J. P., 1994, “Cost Asymmetries in International Subsidy Games: Should Governments Help Winners or Losers”, Journal of International Economics 37, $197-218$.

Petrakis E. and J. Poyago-Theotoky, 2002, "R\&D Subsidies versus R\&D Cooperation in a Duopoly with Spillovers and Pollution," Australian Economic Papers 41, 37-52.

Snow, A. and R.S. Warren, 1996, "The Marginal Cost of Funds: Theory and Evidence," Journal of Public Economics 61, 289-305.

Spencer, B.J. and J.A. Brander, 1983, "International R\&D Rivalry and Industrial Strategy," Review of Economic Studies 50, 707-722.

Stuart, C., 1984, "Welfare Costs Per Dollar of Additional Tax Revenue in the United States," American Economic Review 74, 352-362.

Venables, A.J., 1985, “Trade and Trade Policy with Imperfect Competition: The Case of Identical Products and Free Entry," Journal of International Economics 19, 1-19.

Zhou, D., B.J. Spencer, and I. Vertinsky, 2002, "Strategic Trade Policy with Endogenous Choice of Quality and Asymmetric Costs," Journal of International Economics 56, 205-232. 